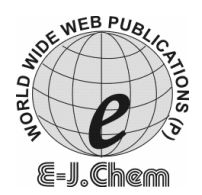

ISSN: 0973-4945; CODEN ECJHAO

E-Journal of Chemistry

http://www.e-journals.net

Vol. 5, No.4, pp. 742-753, October 2008

\title{
Orthophosphoric Acid Activated Babul Seed Carbon as an Adsorbent for the Removal of Methylene Blue
}

\author{
M.SUJATHA, A.GEETHA*, P.SIVAKUMAR and P.N.PALANISAMY \\ Department of Chemistry, Kongu Engineering College, \\ Erode, Tamilnadu, India - 638052 \\ ageetha80@yahoo.co.in
}

Received 11 December 2007; Accepted 5 February 2008

\begin{abstract}
An Experimental and theoretical study has been conducted on the adsorption of methylene blue dye using activated carbon prepared from babul seed by chemical activation with orthophosphoric acid. BET surface area of the activated carbon was determined as $1060 \mathrm{~m}^{2} / \mathrm{g}$. Adsorption kinetics, equilibrium and thermodynamics were investigated as a function of initial dye concentration, temperature and $\mathrm{pH}$. First order Lagergren, pseudo-second order and Elovich kinetic models were used to test the adsorption kinetics. Results were analyzed by the Langmuir, Freundlich and Temkin isotherm models. Based on regression coefficient, the equilibrium data found fitted well to the Langmuir equilibrium model than other models. The characteristics of the prepared activated carbon were found comparable to the commercial activated carbon. It is found that the babul seed activated carbon is very effective for the removal of colouring matter.
\end{abstract}

Keywords: Adsorption, Activated carbon, Methylene blue dye, Kinetics, Isotherm.

\section{Introduction}

India is a highly populated country, safe drinking and domestic water demand is very high. Dying industries are the largest sector of chemical industries in India ${ }^{1}$. Among this textile industry is the largest consumer of dyestuff, consuming more than $80 \%$ of the total production $^{1}$ and they are carcinogenic also ${ }^{2}$. The disposal of coloured wastes into water affects the environment as they are highly toxic to human and aquatic life ${ }^{3,4}$. Dyes usually have synthetic origins and complex aromatic molecular structures. They are highly coloured polymers and fewer biodegradables. Trace amount of dye affects living being with several allergies, reproductive and neurological disorders. One among them is methylene blue $(3,9$ bis dimethyl aminophenazothionium chloride) is a basic dye which is used as a colorant in textile industry. Adverse effect on human /animal health and variety of uses of methylene blue attracted considerable global attention to develop easy and powerful methods for its determination. The present investigation is an attempt to remove methylene blue by adsorption process. Adsorption is an important technique in separation and purification 
process. The objective of this study was to prepare activated carbon from babul seed by chemical activation with ortho phosphoric acid. Large availability of this material around our city attracted us to utilize it as potential adsorbent for the removal of toxic dyes.

Activated carbon adsorption capacity depends on different factors like texture (surface area, pore size distributions), surface chemistry (surface functional groups) and ash content ${ }^{5-8}$. It also depends on adsorptive characteristics like molecular weight, polarity, $\mathrm{pk}_{\mathrm{a}}$, molecular size and functional groups. The solution condition is other factor to be taken into account: $\mathrm{pH}$, adsorptive concentration and presence of other possible adsorptives $^{7-10}$. Adsorption kinetics, equilibrium and thermodynamics were investigated as a function of initial dye concentration, temperature and $\mathrm{pH}$.

\section{Experimental}

\section{Adsorbent preparation}

Babul seed is collected from local area of Erode district. It was dried, charred with excess quantity of ortho phosphoric acid keeping at $120^{\circ} \mathrm{C}$ for $10 \mathrm{~h}$. Then the resultant carbon is washed with excess quantity of distilled water and dried at $110^{\circ} \mathrm{C}$ for 1 hour and stored in a tight lid container for further studies. It is then screened through a mesh sieve with a particle size range of $180-300 \mu \mathrm{m}$.

\section{Adsorbate preparation}

Stock solution (1000 mg/L) of methylene blue is prepared by dissolving $1 \mathrm{~g}$ of dye in $1000 \mathrm{~mL}$ of double distilled water. The stock solutions were diluted with double distilled water to obtain required standard solution. Batch adsorption studies were performed at $30{ }^{\circ} \mathrm{C}, 100 \mathrm{mg}$ of adsorbent is mixed with known initial concentration say $(20,40,60 \& 80 \mathrm{mg} / \mathrm{L}$ respectively) of methylene blue solution and agitated. The adsorbent and the adsorbate were separated by filtration and filterate was analysed for residual methylene blue concentration spectrophotometrically (using Elico make Bio-UV Spectrophotometer, model BL-192) at $\lambda_{\max }=661 \mathrm{~nm}$.<smiles></smiles>

Figure 1. Structure of methylene blue

The surface area was calculated from the nitrogen adsorption isotherm and BET surface area of the activated carbon was determined as $1060 \mathrm{~m}^{2} / \mathrm{g}$. Effect of $\mathrm{pH}$ on the removal of dye were studied using $50 \mathrm{~mL}$ of dye solution of $20 \mathrm{mg} / \mathrm{L}$ initial concentration, adjusted to a desired initial $\mathrm{pH}$ values using $\mathrm{HCl}$ or $\mathrm{NaOH}$ and agitated with $100 \mathrm{mg}$ of adsorbent for 120 minutes. In this study, influence of initial concentration on amount of methylene blue removed is examined.

\section{Adsorption dynamics}

In order to investigate the mechanism of sorption, several kinetic models were tested including Lagergren, Pseudo second order and Elovich model.

\section{Lagergren model}

For a batch contact time process, where rate of sorption of dye on to given adsorbent is proportional to amount of dye sorbed from solution, first order Langergren kinetic equation may be expressed as 


$$
\log q_{e}-q_{t}=\log q_{e}-\left(k_{L} / 2.303\right) t
$$

where,

$\mathrm{q}_{\mathrm{e}}=$ amount of dye adsorbed at equilibrium $(\mathrm{mg} / \mathrm{g})$,

$\mathrm{q}_{\mathrm{t}}=$ amount of dye adsorbed at time $\mathrm{t}(\mathrm{mg} / \mathrm{g})$ and

$\mathrm{k}_{\mathrm{L}}=$ rate constant for first order adsorption $\left(\mathrm{min}^{-1}\right)$.

Hence a linear trace is obtained between the two values $\log \left(\mathrm{q}_{\mathrm{e}}-\mathrm{q}_{\mathrm{t}}\right)$ and $\mathrm{t}$, provided the adsorption follows first order kinetics. In order to examine the efficiency of an adsorbent, this study is useful in removal of adsorbate species from aqueous solution by an adsorbent.

\section{Pseudo second order model}

To describe dye adsorption, modified pseudo second order equation is expressed as follows ${ }^{11}$

$$
\frac{d q_{t}}{d t}=k_{2}\left(q_{e}-q_{t}\right)^{2}
$$

where,

$\mathrm{q}_{\mathrm{e}}=$ amount of dye adsorbed at equilibrium $(\mathrm{mg} / \mathrm{g})$,

$\mathrm{q}_{\mathrm{t}}=$ amount of dye adsorbed at time $\mathrm{t}(\mathrm{mg} / \mathrm{g})$ and

$\mathrm{k}_{2}=$ rate constant for pseudo second order adsorption, $(\mathrm{g} / \mathrm{mg} / \mathrm{min})$.

For the boundary conditions $\mathrm{t}=0$ to $\mathrm{t}=1 \& \mathrm{q}_{\mathrm{t}}=0, \mathrm{q}_{\mathrm{t}}=\mathrm{q}_{\mathrm{t}}$

Intergrated form of equation is as follows,

$$
\frac{1}{q_{e}-q_{t}}=\frac{1}{q_{e}}+k_{2} t
$$

Linear form of equation can be expressed as follows,

$$
\frac{t}{q_{t}}=\frac{t}{k q_{e}^{2}}+\left(\frac{1}{q_{e}}\right) t
$$

Thus a plot of $\mathrm{t} / \mathrm{q}_{\mathrm{t}} V s \mathrm{t}$ of above equation should give a linear relation with a slope of $1 / \mathrm{q}_{\mathrm{e}}$ and an intercept of $1 / \mathrm{k}_{2} \mathrm{q}_{\mathrm{e}}^{2}$

\section{Elovich model}

Elovich or Roginsky-Zeldovich equation is generally expressed as follows ${ }^{12}$

$$
\frac{d q_{t}}{d t}=\alpha e^{-\beta q}
$$

intergrating the rate equation with the boundary condition $\mathrm{t}=0$ to $\mathrm{t}=\mathrm{t}$ and $\mathrm{q}=0$ to $\mathrm{q}=\mathrm{q}$, gives

$$
q_{t}=\frac{1}{\beta} \ln (\alpha \beta)+\frac{1}{\beta} \ln \left(t+t_{0}\right)
$$

where, $\alpha$ and $\beta$ are the parameters of the equation and $t_{0}=1 / \alpha \beta$,

$\alpha$ represents the rate of chemisorption at zero coverage $(\mathrm{mg} / \mathrm{g} / \mathrm{min})$ and $\beta$ is related to the extent of surface coverage and activation energy for chemisorption $(\mathrm{g} / \mathrm{mg})$ where $\mathrm{t}_{\mathrm{o}}<<\mathrm{t}$, then equation (6) is replaced by

$$
q_{t}=\frac{1}{\beta} \ln (\alpha \beta)+\frac{1}{\beta} \ln t
$$

A plot $\mathrm{q}_{\mathrm{t}} V s \ln \mathrm{t} \quad$ gives a straight line and the constants $\alpha$ and $\beta$ are calculated from slope and intercept. 


\section{Isotherm models}

Adsorption isothermal data could be interpreted by the Langmuir, Freundlich and Temkin isotherm models.

\section{Langmuir isotherm}

The study of Langmuir isotherm is essential in assessing the adsorption efficiency of adsorbent. This model was based on assumption of formation of monolayer of adsorbate species onto the surface of adsorbent. This study is useful in optimizing the operating condition for effective adsorption. Langmuir equation is,

$$
\frac{C_{e}}{q_{e}}=\frac{C_{e}}{Q_{0}}+\frac{1}{Q_{0} b}
$$

where,

$\mathrm{q}_{\mathrm{e}}=$ amount of dye adsorbed at equilibrium $(\mathrm{mg} / \mathrm{g})$,

$\mathrm{Ce}=$ equilibrium constant of dye $(\mathrm{mg} / \mathrm{L})$,

$\mathrm{Q}_{0}=$ Langmuir Constant related to adsorption capacity $(\mathrm{mg} / \mathrm{g})$ and

$\mathrm{b}=$ Langmuir Constant related to energy of adsorption capacity $(\mathrm{L} / \mathrm{mg})$.

The values $\mathrm{Q}_{0}$ and $\mathrm{b}$ at different temperatures were determined from slopes and intercepts of the plot of $\mathrm{C}_{\mathrm{e}} / \mathrm{q}_{\mathrm{e}} V s \mathrm{C}_{\mathrm{e}}$. Equilibrium parameter $\mathrm{R}_{\mathrm{L}}$ is represented as follows

$$
R_{L}=\frac{1}{\left(1+b C_{O}\right)}
$$

$\mathrm{C}_{\mathrm{o}}$ is initial dye concentration $(\mathrm{mg} / \mathrm{L})$

$R_{L}$ values between $0 \& 1$ indicate favourable adsorption for all initial concentration and temperature studied. $\mathrm{R}_{\mathrm{L}}$ indicates isotherm shape and whether it is favourable or not as per the criteria given subsequently

\section{Freundlich isotherm}

\begin{tabular}{ll}
\hline $\mathrm{R}_{\mathrm{L}}$ values & Adsorption \\
\hline $\mathrm{R}_{\mathrm{L}}>1$ & Unfavourable \\
$\mathrm{R}_{\mathrm{L}}=1$ & Linear \\
$0<\mathrm{R}_{\mathrm{L}}<1$ & Favourable \\
$\mathrm{R}_{\mathrm{L}}=0$ & Irreversible \\
\hline
\end{tabular}

At equilibrium conditions, adsorbed amount $\mathrm{q}_{\mathrm{e}}$ can be predicted by using Freundlich equation

$$
\log q_{e}=\frac{1}{n} \log C_{e}+\log k_{f}
$$

where,

$\mathrm{q}_{\mathrm{e}}=$ dye concentration in solid at equilibrium $(\mathrm{mg} / \mathrm{g})$,

$\mathrm{Ce}=$ dye concentration in solution at equilibrium, $(\mathrm{mg} / \mathrm{L})$,

$\mathrm{k}_{\mathrm{f}}=$ measure of adsorption capacity and

$\mathrm{n}=$ adsorption intensity.

A plot of $\log \mathrm{q}_{\mathrm{e}} V s \log \mathrm{C}_{\mathrm{e}}$ gives a slope of $1 / \mathrm{n}$ and intercept of $\log \mathrm{k}_{\mathrm{f}}$.

\section{Temkin isotherm}

The derivation of Temkin isotherm assumes that the fall in heat of sorption is linear rather than logarithmic as implied in Freundlich equation. Heat of sorption of all the molecules in the layer would decrease linearly with coverage due to sorbate / sorbent interaction. 
The linear form of the Temkin isotherm can be expressed as,

$$
q_{e}=B \ln A+B \ln C e
$$

where,

$\mathrm{Ce}=$ concentration of the dye at equilibrium $(\mathrm{mg} / \mathrm{L})$,

$\mathrm{q}_{\mathrm{e}}=$ amount of dye adsorbed at equilibrium $(\mathrm{mg} / \mathrm{g})$ and

$\mathrm{RT} / \mathrm{h}=\mathrm{B}$ and $\mathrm{A} \& \mathrm{~h}$ are constants

A plot of $\mathrm{q}_{\mathrm{e}} V s \ln \mathrm{Ce}$ is used to determine the constants A and B.

Adsorption thermodynamics

Rate of a reaction can be found from kinetic studies. But the changes in the reaction can be expected during sorption process require brief idea of thermodynamic parameters. Thermodynamic parameters characterized the equilibrium of a system are Gibbs free energy change $\Delta \mathrm{G}$, enthalpy change $\Delta \mathrm{H}$ and entropy change $\Delta \mathrm{S}$. They are determined using the following equation ${ }^{13,14}$

$$
\Delta G=-R T \ln K_{L}
$$

Where,

$$
K_{L}=q_{0} \cdot b
$$

where,

$\mathrm{q}_{0}$ and $\mathrm{b}$ are Langmuir constants obtained at various temperatures.

Substituting the values of (13) in (12),

$$
\log K_{L}=\left[\frac{\Delta S}{2.303 R}\right]-\left[\frac{\Delta H}{2.303 R T}\right]
$$

Thus the value of $\Delta \mathrm{S} \& \Delta \mathrm{H}$ can be calculated from the intercept and slope of the plot of $\log \mathrm{K}_{\mathrm{L}}$ Vs $1 / \mathrm{T}$.

\section{Results and Discussion}

\section{Effect of initial dye concentration}

The initial concentration of methylene blue solution was varied from 20, 40, 60 and $80 \mathrm{mg} / \mathrm{L}$ and batch experiments were carried out with $100 \mathrm{mg}$ of the adsorbent at $30^{\circ} \mathrm{C}$ and at $\mathrm{pH} 7.0$. An increased percentage removal of methylene blue from 75.10 to $96.41 \%$ observed with 100 $\mathrm{mg}$ of the adsorbent in agitation time of 100 minutes and results are shown in Figure 2. In order to establish equilibration time for maximum uptake and to know the kinetics of adsorption process, the adsorption of methylene blue on adsorbent was studied as a function of contact time. It was found that time of equilibrium as well as time required to achieve a definite fraction of equilibrium adsorption is independent of initial concentration.

\section{Effect of $p H$}

Adsorption is also affected by change in $\mathrm{pH}$ of the solution ${ }^{15,16}$ as shown in Figure 3.The dependence of adsorption process on $\mathrm{pH}$ of dye solution was studied by varying $\mathrm{pH}$ of dye solution from 2 to 11 . The hydrogen ion concentration $(\mathrm{pH})$ primarily affects the degree of ionization of the dyes and the surface properties of the adsorbents. The $\%$ of dye adsorbed increased from 89.41 to 94.12 with increase in $\mathrm{pH}$ from 2 to 11 at temperature of $30^{\circ} \mathrm{C}$. This is attributed to the increasing electronegative charge on the adsorbent as the $\mathrm{pH}$ of the solution is increased. As the adsorbent is negatively charged, the increasing electrostatic attraction between positive adsorbate dye species and the negative adsorbent particles would lead to increased adsorption of dyes. The optimum $\mathrm{pH}$ value for the adsorption of methylene 
blue was observed 13.40 by Ravikumar et $\mathrm{al}^{17}$. Though there is no much variation of adsorption above $\mathrm{pH}$ of 5.0. For further studies $\mathrm{pH}$ fixed as 7.0 for convenience.

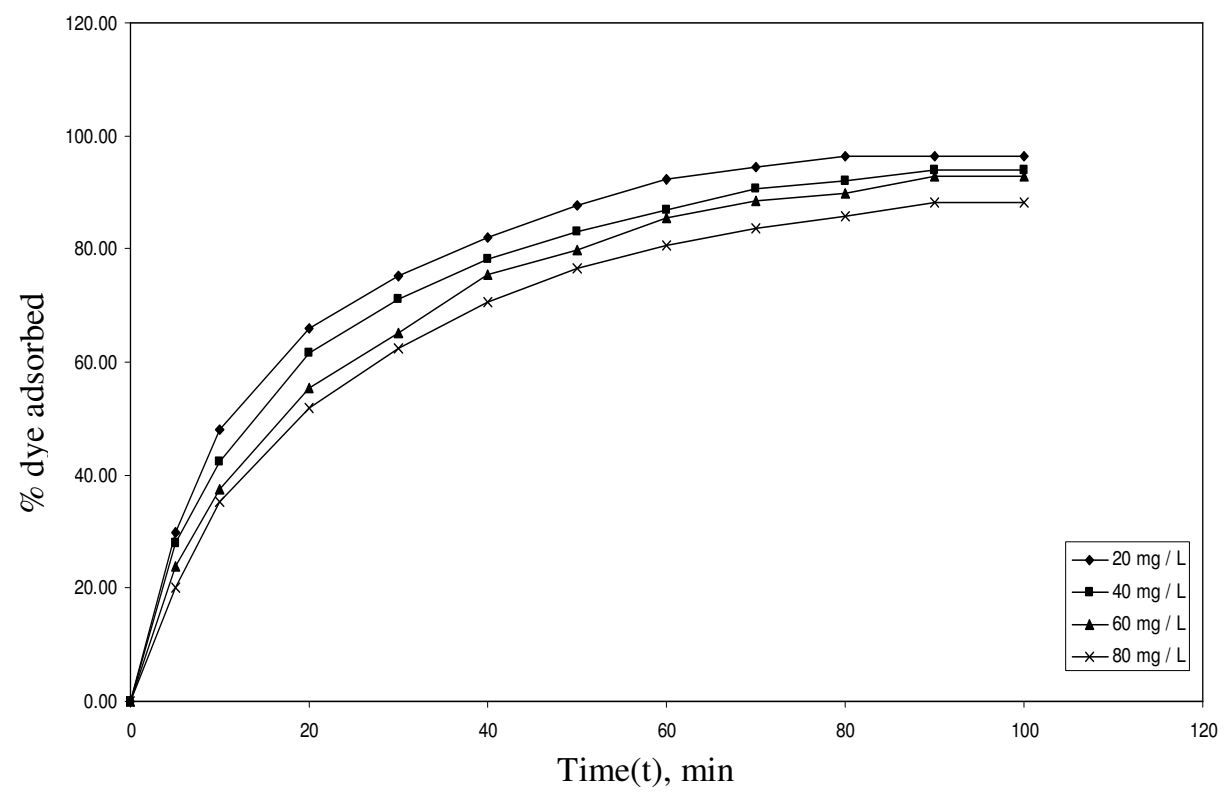

Figure 2. Effect of agitation time on adsorption -initial concentration variation

\section{Effect of $p H$}

Adsorption is also affected by change in $\mathrm{pH}$ of the solution ${ }^{15,16}$ as shown in Figure 3 . The dependence of adsorption process on $\mathrm{pH}$ of dye solution was studied by varying $\mathrm{pH}$ of dye solution from 2 to 11 . The hydrogen ion concentration $(\mathrm{pH})$ primarily affects the degree of ionization of the dyes and the surface properties of the adsorbents. The $\%$ of dye adsorbed increased from 89.41 to 94.12 with increase in $\mathrm{pH}$ from 2 to 11 at temperature of $30^{\circ} \mathrm{C}$. This is attributed to the increasing electronegative charge on the adsorbent as the $\mathrm{pH}$ of the solution is increased. As the adsorbent is negatively charged, the increasing electrostatic attraction between positive adsorbate dye species and the negative adsorbent particles would lead to increased adsorption of dyes. The optimum $\mathrm{pH}$ value for the adsorption of Methylene Blue was observed 13.40 by Ravikumar et $a l^{17}$. Though there is no much variation of adsorption above $\mathrm{pH}$ of 5.0. For further studies $\mathrm{pH}$ fixed as 7.0 for convenience.

\section{Sorption kinetics}

In order to examine the controlling mechanisms of adsorption process first-order kinetics model, pseudo second order kinetics and Elovich models are used to test the experimental data.

\section{First order kinetics}

Langergren first order plot for the adsorption of methylene blue at various initial concentration is given in the Figure 4. The applicability of Lagergren model suggests the formation of a monomolecular layer of dye species onto surface of adsorbent. The study of influence of initial dye concentration on Lagergren rate constant from Table 1 shows a decrease in rate constant with increase in initial dye concentration. 


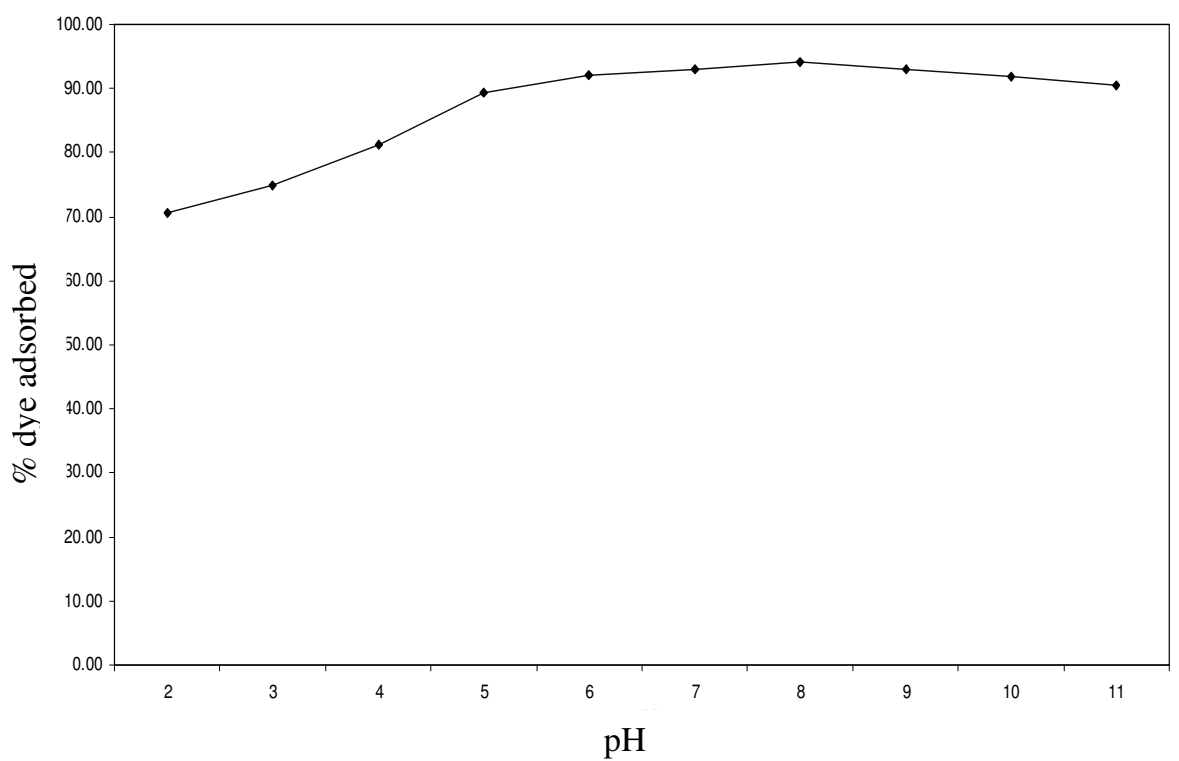

Figure 3. Effect of $\mathrm{pH}$ on methylene blue adsorption

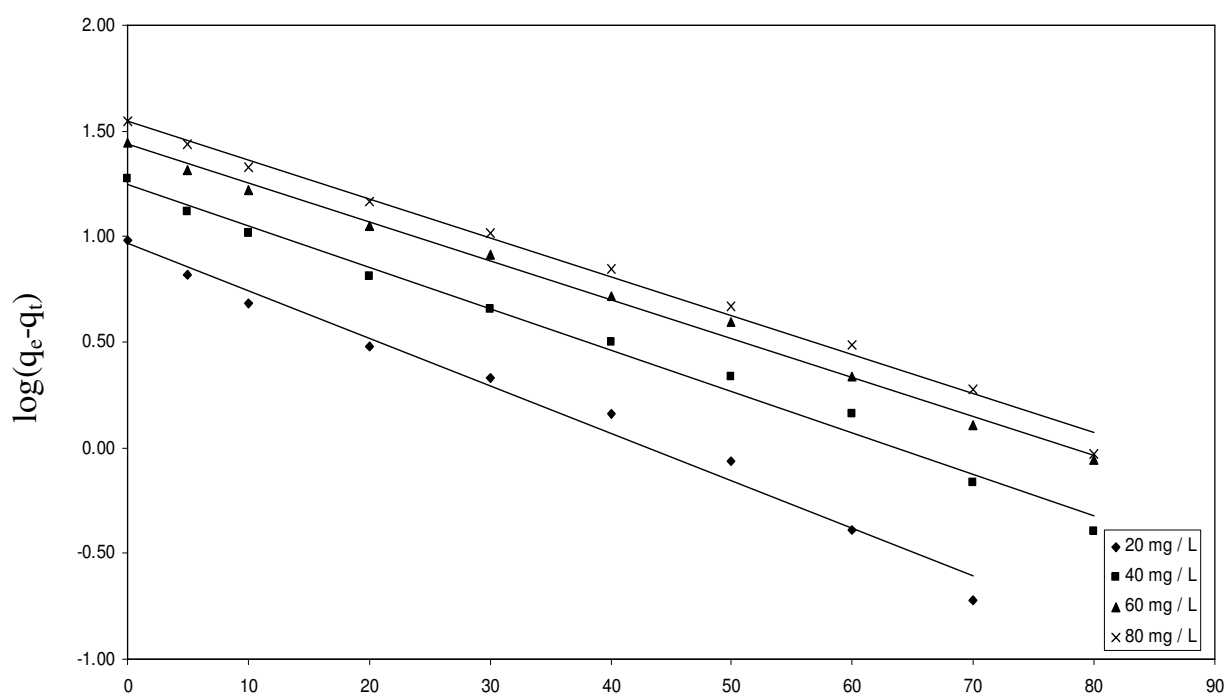

Time(t), min

Figure 4. First order plot -initial methylene blue concentration variation

\section{Pseudo second order model}

Figure 5 shows that pseudo second order equation at various initial dye concentration $(20,40,60$ $\& 80 \mathrm{mg} / \mathrm{L}$ ). These plots show that data had good correlation coefficients when pseudo second order equation was employed and was possible to ascertain from them whether rate determining process is a chemical reaction. Thus increasing dye concentration from 20 to $80 \mathrm{mg} / \mathrm{L}$, equilibrium sorption capacity $\mathrm{q}_{\mathrm{e}}$ increases. methylene blue sorbed at any contact time increases. 


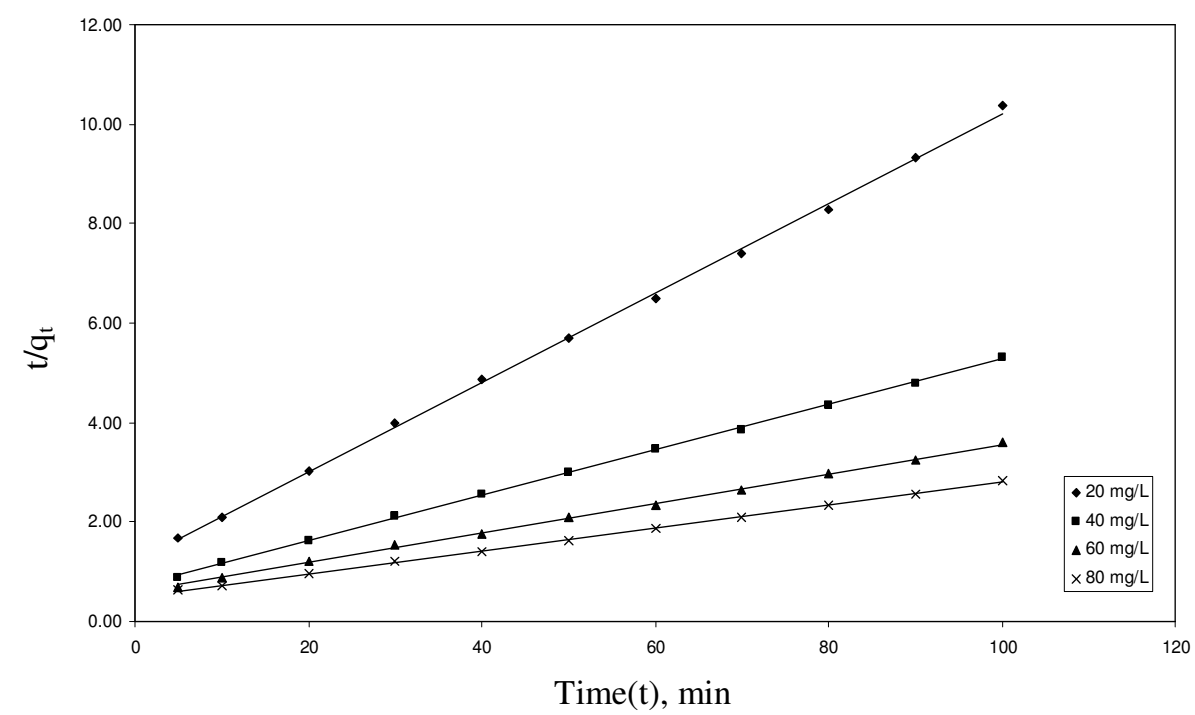

Figure 5. Pseudo second order plot-initial methylene blue concentration variation

\section{Elovich model}

The results of sorption of methylene blue onto babul seed carbon have been represented in the form of Elovich equation in Figure 6 at various dye concentration (20, 40, 60 \& $80 \mathrm{mg} / \mathrm{L})$. From the plot of linear relationship between the amount of methylene blue adsorbed, $\mathrm{q}_{\mathrm{t}}$ and $\ln t$ was established. Table 1 shows the kinetic constants obtained from Elovich equation. It will be seen from the data that the values of $\alpha$ and $\beta$ varied as a function of methylene blue concentration. Thus an increasing the initial concentration of methylene blue from $20 \mathrm{mg} / \mathrm{L}$ to $80 \mathrm{mg} / \mathrm{L}$, value of $\alpha$ increases and $\beta$ value decreases. Although Elovich equation does not provide any mechanistic evidence, it has proved suitable for highly heterogenous systems of which adsorption of methylene blue onto babul seed carbon is undoubtedly such a case.

Table 1. Kinetic model values for adsorption of methylene blue onto activated babul seed carbon

\begin{tabular}{ccccccccccc}
\hline $\begin{array}{c}\text { Concentration } \\
\mathrm{mg} / \mathrm{L}\end{array}$ & \multicolumn{3}{c}{$1^{\text {st }}$ Order } & \multicolumn{4}{c}{ Pseudo second order } & \multicolumn{3}{c}{ Elovich } \\
\cline { 2 - 3 } & $\mathrm{k}_{\mathrm{L}}$ & $\mathrm{q}_{\mathrm{e}}$ & $\mathrm{r}^{2}$ & $\mathrm{q}_{\mathrm{e}}$ & $\mathrm{k}_{2}$ & $\mathrm{~h}$ & $\mathrm{r}^{2}$ & $\beta$ & $\alpha$ & $\mathrm{r}^{2}$ \\
\hline 20 & 0.05182 & 9.2725 & 0.9853 & 11.11 & 0.0067 & 0.8273 & 0.9991 & 0.4347 & 3.55290 & 0.9881 \\
40 & 0.04514 & 17.6278 & 0.9905 & 21.88 & 0.00296 & 1.4152 & 0.9996 & 0.2171 & 5.72216 & 0.9938 \\
60 & 0.04214 & 27.1300 & 0.9951 & 33.67 & 0.0015 & 1.7007 & 0.999 & 0.1368 & 8.37953 & 0.9946 \\
80 & 0.04261 & 35.3427 & 0.9925 & 43.48 & 0.00107 & 2.0198 & 0.9995 & 0.1194 & 9.43952 & 0.9834 \\
\hline
\end{tabular}

Isotherm modeling

Langmuir Adsorption Isotherm

Adsorption isotherm obtained by fixing adsorbent dosage of $100 \mathrm{mg}$ and 100 minutes of agitation time is shown in the Figure 7. The result of Langmuir adsorption isotherm for the selected adsorbent/adsorbate system is given in the Table 2. The adsorption capacity $\mathrm{Q}_{0}$ values found to be comparable with commercial activated carbon. The values of $\mathrm{R}_{\mathrm{L}}$ obtained in this study indicate the applicability of Langmuir adsorption isotherm. The calculated value $\mathrm{R}^{2}$ confirm the applicability of Langmuir adsorption isotherm. 


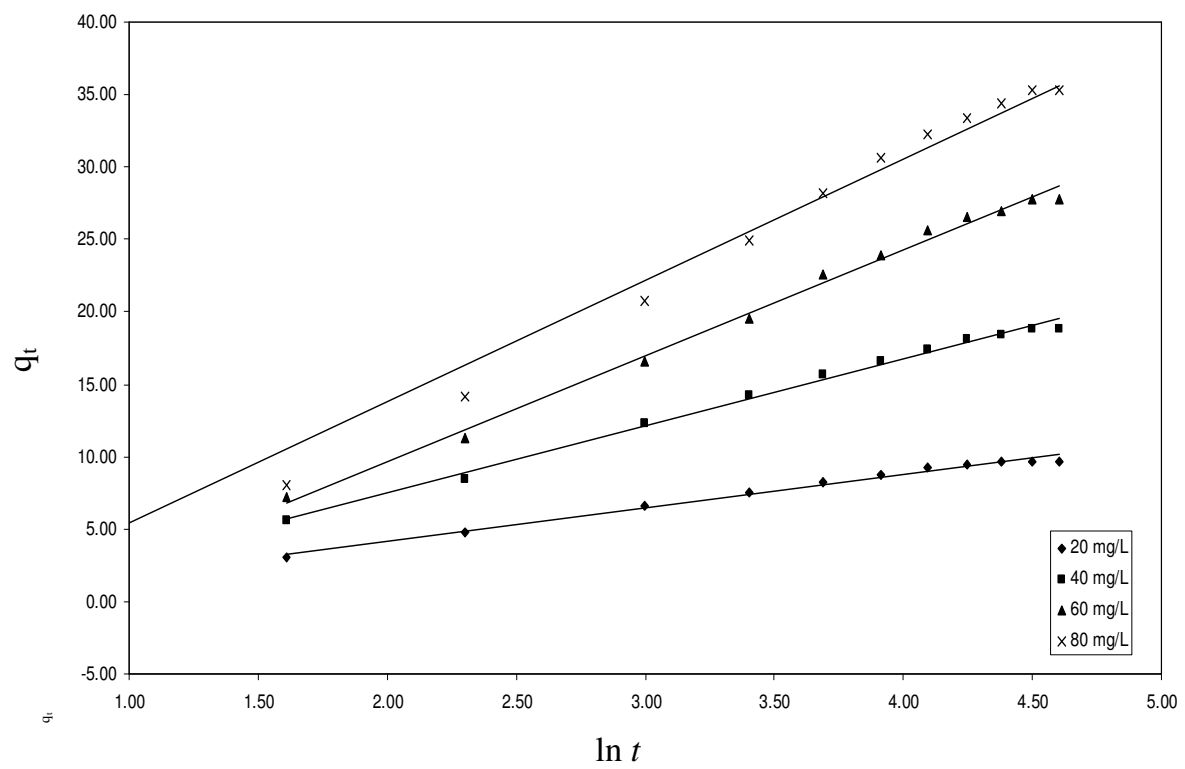

Figure 6. Elovich plot-initial concentration variation

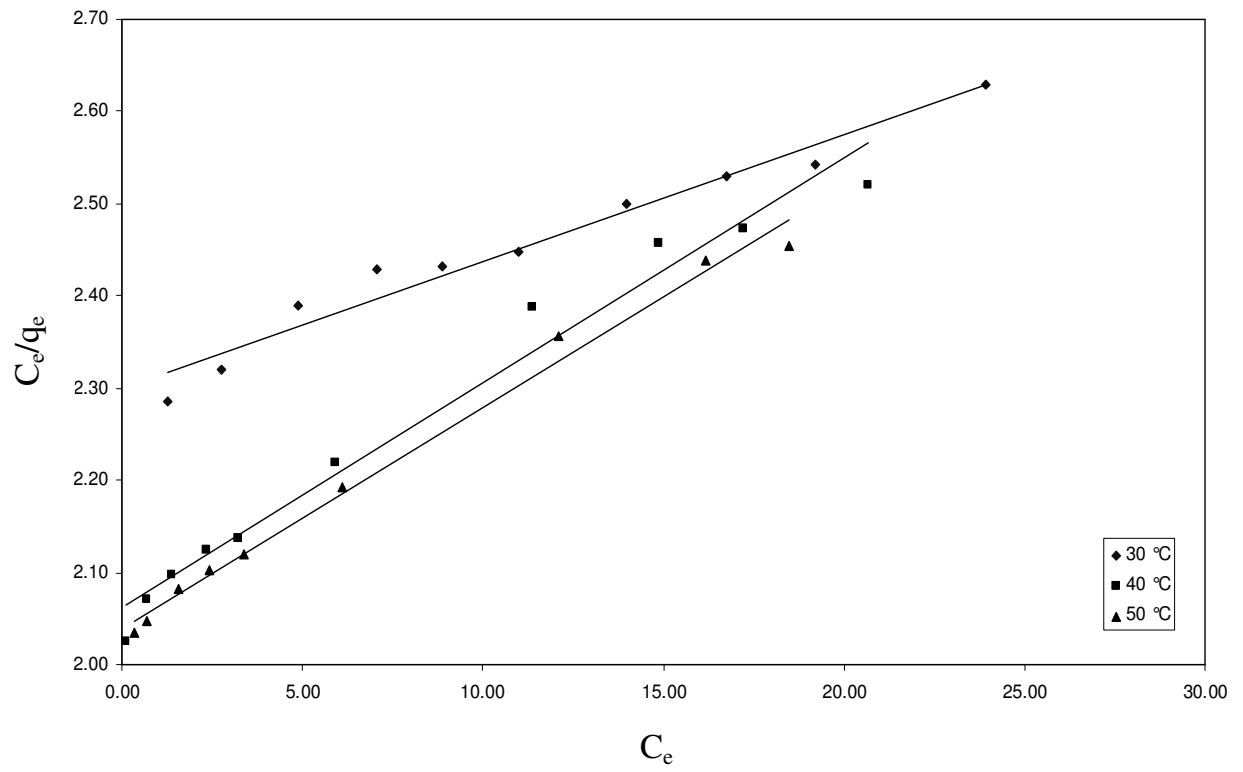

Figure 7. Langmuir plot-temperature variation

\section{Freundlich adsorption isotherm}

Freundlich plot for the adsorption of methylene blue on to babul seed activated carbon is given in the Figure 8 and the results of Freundlich plot are given in the Table 2. It shows that the values of adsorption intensity $1 / \mathrm{n}>1$ reveal that applicability of Freundlich adsorption is not good compared to Langmuir Adsorption Isotherm. Study of temperature effects on Freundlich parameters reveals increasing trend in adsorption capacity with increase in temperature. 


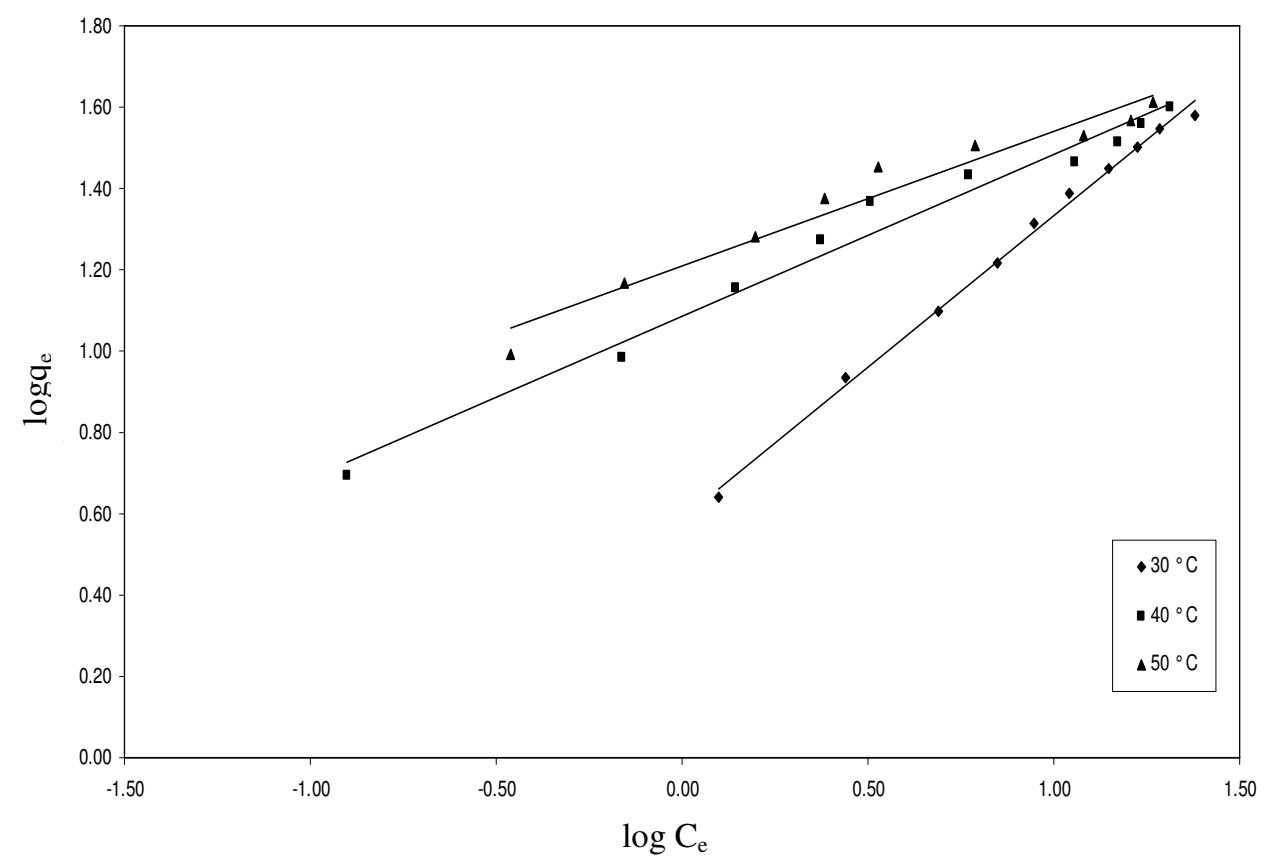

Figure 8. Freundlich plot-temperature variation

Table 2. Parameters of Langmuir adsorption isotherm and Freundlich adsorption isotherms for methylene blue adsorption calculated for 100 minutes of agitation time onto activated babul seed carbon

\begin{tabular}{cccccccccc}
\hline \multirow{2}{*}{ Temperature ${ }^{\circ} \mathrm{C}$} & \multicolumn{3}{c}{ Langmuir adsorption isotherm } & \multicolumn{3}{c}{ Freundlich adsorption isotherm } \\
\cline { 2 - 9 } & $\mathrm{b}, \mathrm{L} / \mathrm{mg}$ & $\mathrm{Q}_{\mathrm{o}}, \mathrm{mg} / \mathrm{g}$ & $\mathrm{R}_{\mathrm{L}}$ & $\mathrm{R}^{2}$ & $1 / \mathrm{n}$ & $\mathrm{n}$ & $\mathrm{k}_{\mathrm{f}}$ & $\mathrm{R}^{2}$ \\
\hline 30 & 0.006003 & 72.46 & 1.060 & 0.9954 & 0.7462 & 1.34 & 3.895 & 0.9963 \\
40 & 0.011887 & 40.81 & 1.119 & 0.9870 & 0.3984 & 2.51 & 12.164 & 0.9787 \\
50 & 0.011767 & 41.66 & 1.118 & 0.9912 & 0.3289 & 3.04 & 16.221 & 0.9552 \\
\hline
\end{tabular}

\section{Temkin adsorption isotherm}

Temkin sorption potential increases with increase in temperature and reached maximum value at $50^{\circ} \mathrm{C}$. However model is unable to describe data, compared to other two parameter models as low correlation coefficients was observed.

Table 3. Parameters of Temkin adsorption isotherm of methylene blue onto activated babul seed carbon

\begin{tabular}{cccc}
\hline Temperature ${ }^{\circ} \mathrm{C}$ & $\ln \mathrm{A}$ & $\mathrm{B}$ & $\mathrm{R}^{2}$ \\
\hline 30 & -0.2489 & 11.93 & 0.935 \\
40 & 2.1779 & 6.849 & 0.9467 \\
50 & 2.3504 & 7.413 & 0.9827 \\
\hline
\end{tabular}




\section{Thermodynamic parameters}

The heat of adsorption was calculated by plotting a graph of $\log \mathrm{K}$ versus reciprocal of temperature as shown in Figure $10 . \Delta \mathrm{H}$ and $\Delta \mathrm{S}$ were got from slope and intercept of Vant Hoff plot. The negative value of free energy change $\Delta \mathrm{G}$ indicate the feasibility and spontaneous nature of adsorption of methylene blue. $\Delta \mathrm{H}$ value suggests endothermic nature of methlyene blue onto babul seed carbon. Positive value of $\Delta S$ is due to increase randomness during adsorption of methylene blue. The behavior similar to this was also observed by Amina et $a l^{18}$ for the adsorption of methylene blue The reorientation or restructuring of water around the nonpolar solute or surface is very unfavourable in term of entropy, since it disturbs the existing water structure and imposes a new and more ordered structure on the surrounding water molecules. As a result of adsorption of methylene blue onto activated carbon surface, the number of water molecule surrounding the methylene blue decreases and thus the degree of freedom of the water molecule increases. Therefore, the positive value of entropy suggested the increased randomness at the solid-solution interface during the adsorption of methylene blue.

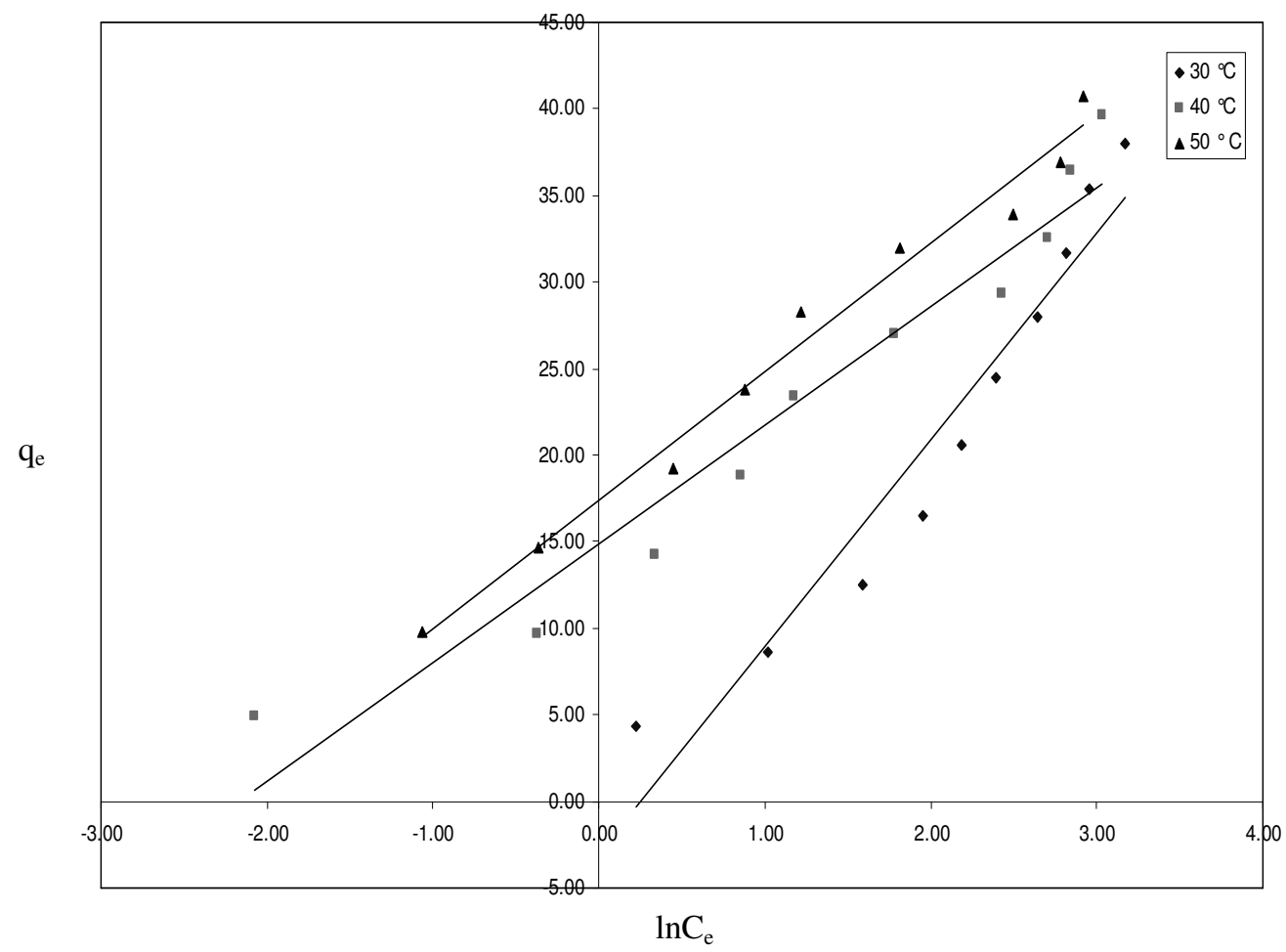

Figure 9. Temkin plot-temperature variation

Table 4. Thermodynamic parameters

\begin{tabular}{cccc}
\hline Temperature ${ }^{\circ} \mathrm{C}$ & $\Delta \mathrm{H}$ & $\Delta \mathrm{S}$ & $\Delta \mathrm{G}$ \\
\hline 30 & & & -353.6277 \\
40 & -71.0733 & 9.4184 & -447.81 \\
50 & & & -541.99 \\
\hline
\end{tabular}




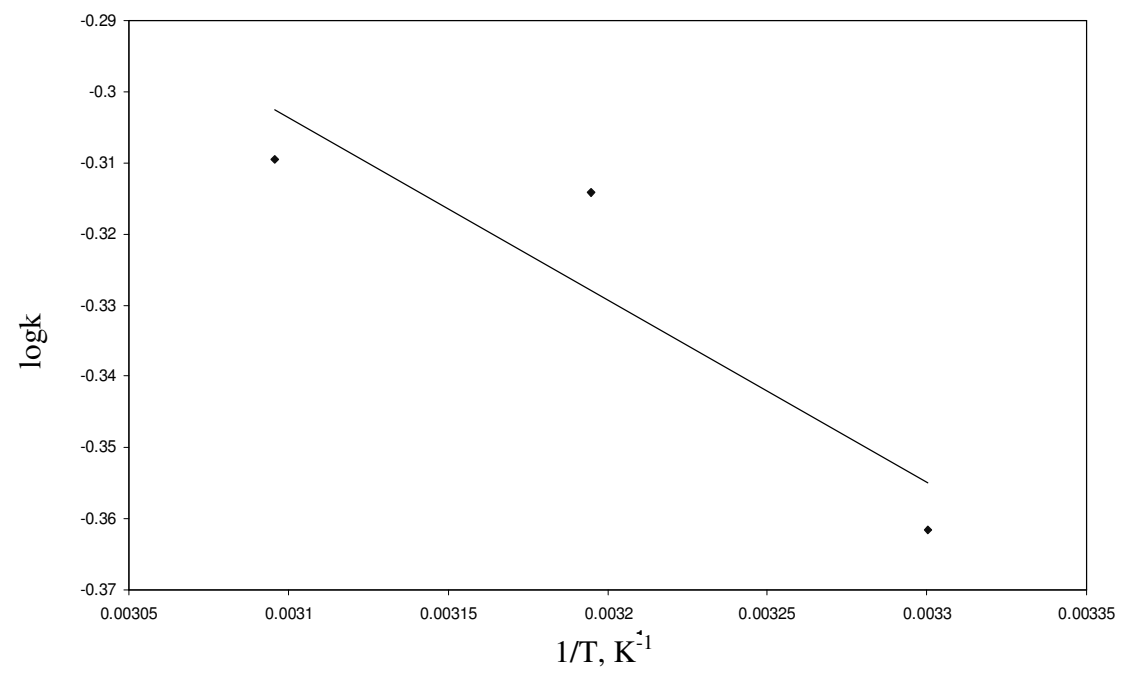

\section{Conclusions}

Figure 10. Vant Hoff's plot

Adsorption of methylene blue is dependent on initial concentration and agitation time. The $\%$ of dye adsorbed increased with increase in $\mathrm{pH}$ at temperature of $30^{\circ} \mathrm{C}$. Based on the regression coefficient value, the adsorption of methylene blue on to babul seed activated carbon followed second order kinetics. The values of $\mathrm{R}_{\mathrm{L}}<1$ obtained indicate the applicability of Langmuir adsorption isotherm. Study of temperature affects on Freundlich parameters reveals increasing trend in adsorption capacity with increase in temperature. Applicability of Freundlich adsorption is not good compared to Langmuir adsorption isotherm. It is an endothermic reaction based on enthalpy change value. The data obtained through this work supports that babul seed carbon is an effective low cost adsorbent for removal of methylene blue from aqueous solution.

\section{References}

1. Kothari industrial directory of India edited by Arokiaswamy.S (Kothan Enterprises Publication, Madras, (India) 1994.

2. $\quad$ Mall I D and Upadhyay S N, IPPTA, 1995, 7(1), 51.

3. Lee C K, Low K S and Gan P, Environ Technol., 1999, 20, 99-104.

4. Pappic S, Koprivanac N and Metes A, Environ Technol., 2000, 21, 97-105.

5. Bansal R C, Donnet J and Stoeckli H F, Active carbon, Dekker, New York, 1988.

6. Gregg S J and Sing K S W, Adsorption, surface area \& porosity, Acdemic press, London, 1982.

7. Radovic L R, Silva I F, Ume J I, Menendez J A, Leony Leon C A and Scaroni A W, Carbon, 1997, 35, 1339.

8. $\quad$ Karanfil T and Kilduff J E, Environ Sci Technol., 1999, 33, 3217.

9. Nouri S and Haghseresht F, Adsorb Sci Technol., 2002, 20, 417.

10. Haghseresht F, Nouri S, Finnerty J J and G Q Lu, J Phys Chem., 2002, 106, 10935.

11. H O Y S and Mcay G, Adsorp Sci Technol., 2000, 18, 639-650.

12. Chien S H and Clayton W R, Soil Sci Soc Am J., 1980, 44, 265-268.

13 Sumanjit and Prasad N, Indian J Chem., 2001, 40A, 388-391.

14. Stephen Inbaraj and Sulochana N, Indian J Chem Technol., 2002, 9, 201-208.

15. (a) Iqbal M J and Hussain M, J Chem Soc Pak., 1993, 15(1), 7-10; (b) Iqbal M J, Hussain M, J Chem Soc Pak., 1993, 15(1), 93-97.

16. Alkan M, Demirbas O, Celikcapa S and Dogan M, J Hazard Mater., 2004, 116, 135-145.

17. Ravikumar K, Deebika B and Balu K, J Hazard Mater., 122 (1-2), 2005, 75-83.

18. Amina A A, Abdel-Nasser A E, Soheir A K and El-Nabarawy, Adsorption Sci Technol., 2004, 22(5), 411-426. 


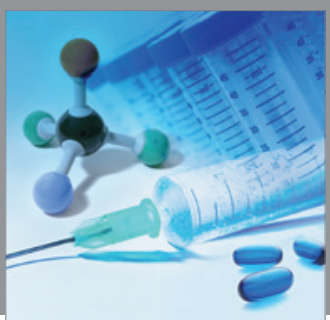

International Journal of

Medicinal Chemistry

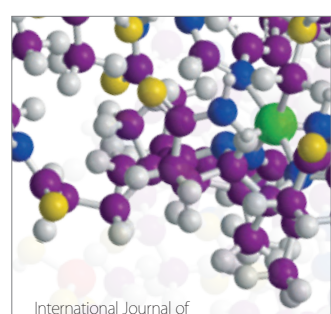

Carbohydrate Chemistry

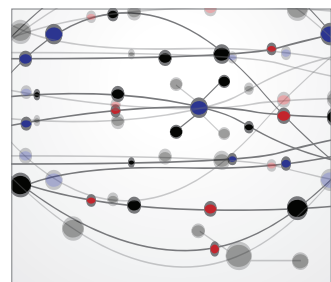

The Scientific World Journal
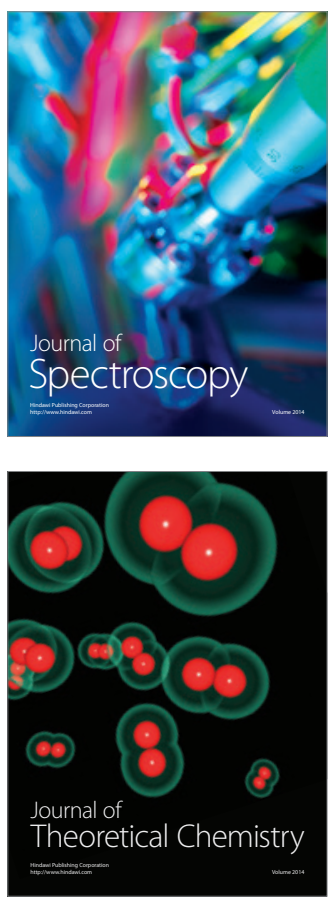
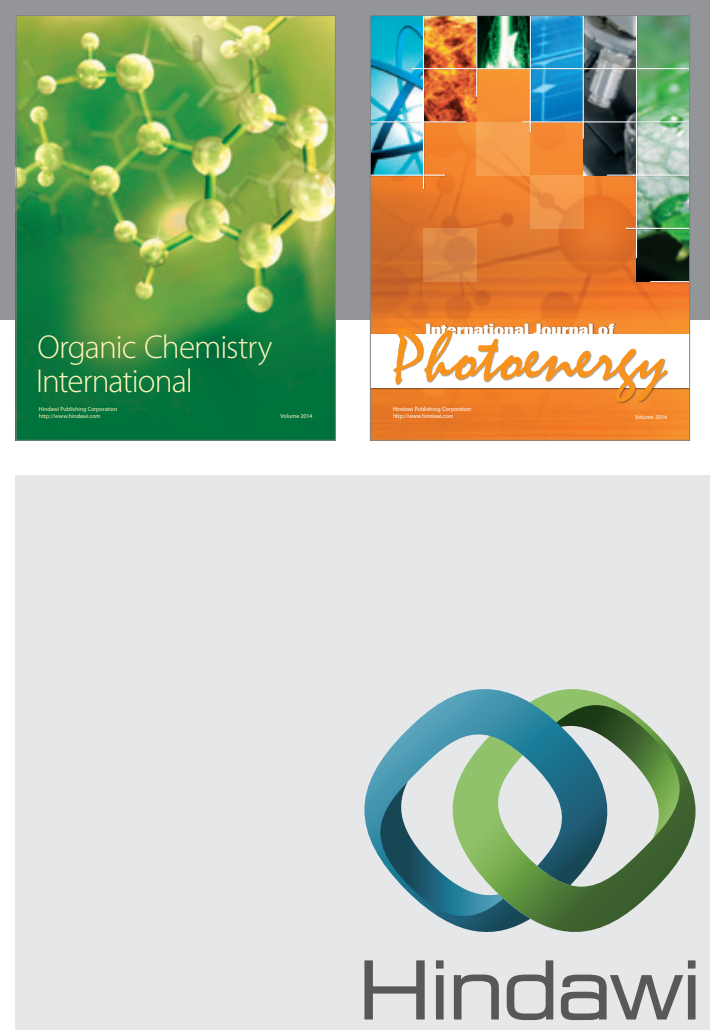

Submit your manuscripts at

http://www.hindawi.com
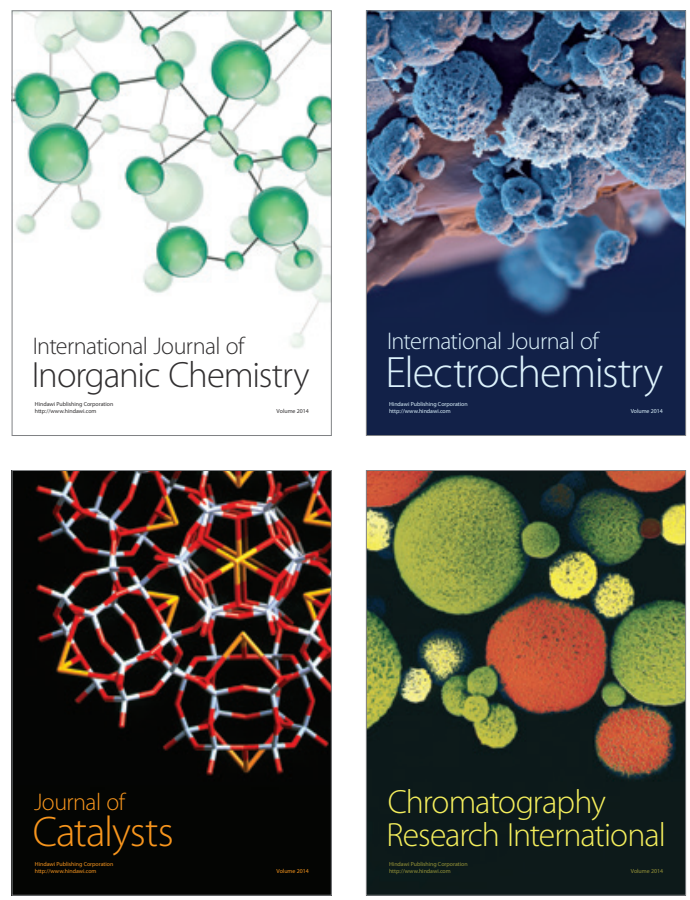
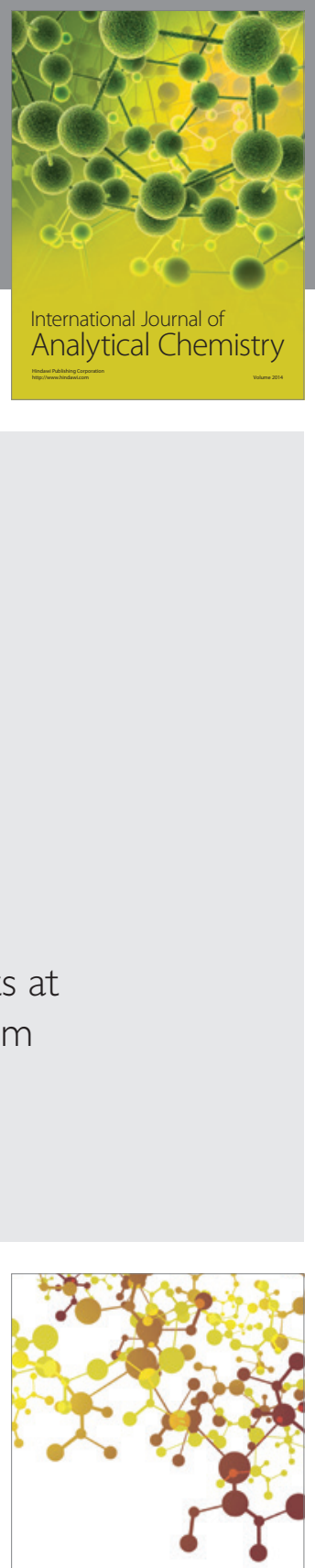

Journal of

Applied Chemistry
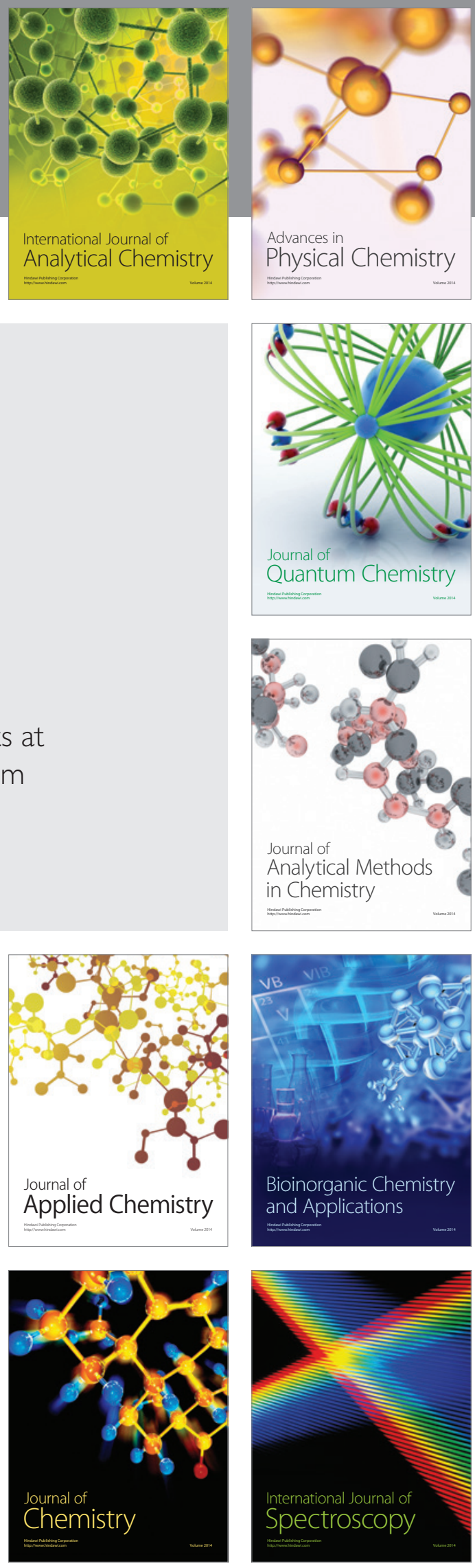